\title{
Right to left interatrial communications after the modified Fontan procedure: identification and management with transcatheter occlusion
}

\author{
Huei-song Hsu, David G Nykanen, William G Williams, Robert M Freedom, Lee N Benson
}

\begin{abstract}
Objective-To describe unusual venous communications from the right to the left atrium resulting in cyanosis after the modified Fontan procedure, and their management with transcatheter occlusion.
\end{abstract}

Methods-Between September 1992 and November 1994, eight patients were assessed for persistent cyanosis after a modified Fontan procedure. Desaturation was found to be caused by unusual venous shunts originating at atrial level, and transcatheter occlusion with either a double umbrella or coil was attempted.

Results-Three types of venous channels were identified. The first type of communication consisted of thin long tortuous channels originating from the right atrial wall, and draining into the left atrium through a capillary network. The second type of communication was in the superior anterior portion of the atrial baffle, incorporating the pectinate muscles of the right atrium, draining into the neoleft atrium. These channels were shorter and often fanned out into small vessels toward the right atrial appendage. In each instance, the shunts were in the superior suture line of a lateral tunnel modification of the Fontan procedure. The third type of communication originated from the inferior vena cava, connecting inferior phrenic veins to pericardial veins and subsequently to the left atrium, at or close to the ostium of the left pulmonary veins. Before device occlusion, the room air aortic oxygen saturation was 88 (SD 4) $\%$ (range $84 \%$ to $94 \%$ ), and increased to $95(3) \%$ (range $91 \%$ to $100 \%$ ) following occlusion ( $P L \ll 0.001)$. The mean right atrial pressure was $14(4) \mathrm{mm} \mathrm{Hg}$ and remained unchanged after occlusion. In six patients there was complete shunt obliteration, while in two both occluded with umbrella devices, a small residual leak persisted. No complication occurred during or immediately after catheterisation.

Conclusions-Unusual venous communications can evolve after the Fontan procedure, resulting in the development or persistence of cyanosis. Some of these communications may be present preoperatively as normal veins draining into the right atrium, enlarging with the increased atrial pressure after surgery. These observations affect long term function after the Fontan procedure.
Transcatheter occlusion of these communications is technically feasible and effective, although recurrence may occur.

(Br Heart f 1995;74:548-552)

Keywords: Fontan procedure; right to left shunt; embolisation

In 1971, Fontan and Baudet ${ }^{1}$ described a surgical technique for palliation of patients with tricuspid atresia. Since then the technique of creating an atrium dependent circulation has undergone many modifications, and has become the treatment goal of many management algorithms. An atrium dependent circulation separates the pulmonary and systemic venous return, eliminating cyanosis and reducing ventricular work, but at a cost of a raised central venous pressure.

Residual atrial shunts after the procedure resulting in persistent cyanosis requiring reoperation were reported early by Fontan and his colleagues. $^{2}$ Subsequently, various unusual venous communications have been observed including superior vena caval or innominate vein to left atrial channels, pulmonary artery to pulmonary vein communications, coronary sinus to left atrial shunts (including the unsuspected unroofed coronary sinus) when the coronary sinus remained within the right atrial chamber, ${ }^{34}$ and the development of right atrial to left atrial venous communications. ${ }^{5}$ In these early series, reoperation was the treatment of choice if the shunting resulted in severe systemic desaturation at rest or with exercise. Recently, transcatheter occlusion or embolisation of such interatrial right to left communications have been reported after the procedure ${ }^{67}$ or when they have been created intentionally at surgery. ${ }^{8}$

We have encountered eight cases of unusual venous communications producing right to left shunt at atrial level, evident after creation of an atrium dependent circulation, different from coronary sinus to left atrial shunt. ${ }^{67}$ These communications appeared suitable for transcatheter occlusion because of their morphology, and we report the early results from embolisation.

\section{Methods}

PATIENT POPULATION

Since 1976, 426 Fontan procedures (including 80 so called fenestrated Fontan procedures) have been performed at the Hospital 
Patient characteristics

\begin{tabular}{|c|c|c|c|c|c|c|}
\hline \multirow[b]{2}{*}{ Patient } & \multirow{2}{*}{$\begin{array}{l}\text { Age } \\
\text { (years) }\end{array}$} & \multirow{2}{*}{$\begin{array}{l}\text { Diagnosis } \\
\text { (dominant ventricle) }\end{array}$} & \multirow{2}{*}{$\begin{array}{l}R A P \\
(m m \mathrm{Hg}) \\
\text { preocclusion }\end{array}$} & \multicolumn{2}{|c|}{$\mathrm{SaO}_{2}(\%)$} & \multirow{2}{*}{$\begin{array}{l}\text { Time (months) } \\
\text { from Fontan } \\
\text { to occlusion }\end{array}$} \\
\hline & & & & preo & m postocclusion & \\
\hline 1 & 3 & $\underset{\text { (RV) }}{\text { HLHS }}$ & 13 & 94 & 100 & 6 \\
\hline 2 & $4 \cdot 1$ & $\begin{array}{l}\text { Hypoplastic RV } \\
\text { (LV) }\end{array}$ & 11 & 85 & 91 & 12 \\
\hline 3 & $8 \cdot 9$ & $\begin{array}{l}\text { DORV, hypoplastic LV } \\
\text { (RV) }\end{array}$ & 8 & 91 & 96 & 58 \\
\hline 4 & 3.5 & $\begin{array}{l}\text { AVSD, hypoplastic LV } \\
\text { (RV) }\end{array}$ & 12 & 87 & 93 & 5 \\
\hline 5 & 4 & $\begin{array}{l}\text { DILV } \\
\text { (LV) }\end{array}$ & 15 & 89 & 94 & 15 \\
\hline 6 & $6 \cdot 8$ & $\begin{array}{l}\text { Absent left connection } \\
\text { (LV) }\end{array}$ & 10 & 90 & 93 & 5 \\
\hline 7 & $2 \cdot 8$ & $\begin{array}{l}\text { DIRV, DORV } \\
\text { (RV) }\end{array}$ & 13 & 85 & 96 & 1 \\
\hline 8 & $16 \cdot 6$ & $\begin{array}{l}\text { DORV, Hypoplastic LV } \\
\text { (RV) }\end{array}$ & 23 & 84 & 95 & 72 \\
\hline
\end{tabular}

RAP, right atrial pressure; $\mathrm{SaO}_{2}$, aortic oxygen saturation; HLHS, hypoplastic left heart syndrome; RV, right ventricle; LV, left ventricle; DORV, double outlet right ventricle; AVSD, atrioventricular septal defect; DILV, double inlet left ventricle; DIRV, double inlet right ventricle.

for Sick Children, Toronto, at a mean age of $6 \cdot 7(\mathrm{SD} 8 \cdot 0)$ years. Between September 1992 and November 1994, eight patients (three males, five females) who had previously undergone the procedure at a mean age of $3 \cdot 5(1.4)$ years, were found to have an unusual venous communication at the atrial level contributing to persistent cyanosis. The median age at the time of occlusion was $4 \cdot 1$ years (range 2.8 to 16.6 years), median body weight $18.7 \mathrm{~kg}$ (range 12.9 to $54.2 \mathrm{~kg}$ ), and median interval from surgery nine months (range one month to six years). The clinical characteristics of the patients are presented in the table. Catheter angiographic investigations were prompted to determine the aetiology of the persistent cyanosis in one (patient 8 ), or as an incidental finding in seven at the time of anticipated transcatheter closure of the fenestrated Fontan. ${ }^{8}$ Except for patient 8, all patients received a fenestrated Fontan procedure using a lateral tunnel technique. ${ }^{9}$ Preoperative cardiac catheterisations were performed to assess risk factors for the Fontan procedure, and angiograms were reviewed documenting the absence of such a venous communication. The mean right atrial pressure at that time was $3(1) \mathrm{mm} \mathrm{Hg}$.

Informed parental consent was obtained before device occlusion procedures, and catheterisations were performed under general anaesthesia. While breathing room air, a full haemodynamic study was performed and angiograms obtained in the pulmonary branch arteries, superior and inferior vena cava, and ventricle to determine the source of the right to left shunt or if any unsuspected lesions were present. Subsequently, a right atrial angiogram was obtained in the anteroposterior and lateral projections to localise the anticipated right to left shunt through either the surgical fenestration or the acquired shunt. Axial modifications were made to identify residual leaks more precisely where necessary. In three patients, incidental to the surgical fenestration, additional sources of right to left shunting were identified during right atrial angiography with the fenestration balloon occluded.
METHOD OF OCCLUSION

The occluder delivery system was introduced from the right atrium, across the communications, and the channels were occluded with a variety of devices. After occlusion either selective or right atrial axial angiography was repeated to confirm occluder position and the extent of any residual or additional shunts. The right atrial pressure and aortic oxygen saturation were measured before and after occlusion.

Two vascular occluding implants were employed: a double umbrella (USCI double umbrella occluder, Bard) or a spring stainless steel coil (Gianturco type, Cook). Two sizes of umbrella device were used, a $12 \mathrm{~mm}$ or a $17 \mathrm{~mm}$ prosthesis. The delivery system modification and transcatheter occlusion technique were similar to that for closure of the persistently patent ductus arteriosus as described previously. ${ }^{1011}$ Several sized occluding coils were also used (MWCE-35-3-3, MWCE-353-5, MWCE-35-5-5), and delivered using a $5 \mathrm{~F}$ right coronary catheter (Cordis) positioned within the communicating vessels. The coil was implanted coaxially with an 0.035 inch guidewire (Newton type, Cook), and delivered using previously described techniques. ${ }^{12}$

\section{DATA ANALYSIS}

Data are expressed as the mean(SD). Statistical analysis of continuous data was performed by using Student's $t$ test. A P value of $<0.05$ was considered significant.

\section{Results}

Eight patients had attempted transcatheter occlusive device implantation: seven had devices placed using a femoral venous approach, while one had a device implant through the internal jugular vein, because of the angle of the communication and location, originating from the high anterior right atrial wall. Transoesophageal, echocardiography was helpful for positioning the occluding device. Of the eight patients, the venous shunts were occluded with a double umbrella occluder in five, and a coil in three. Of the seven fenestrated Fontan patients, the fenestration was found to have closed spontaneously in four (patients 2, 3, 5, and 6), and in three patients, the fenestration was closed successfully with a $12 \mathrm{~mm}$ umbrella device before attempting device occlusion of the venous shunt.

\section{SHUNT MORPHOLOGY}

Three types of venous channel were identified. The first type consisted of thin long tortuous channels originating from the right atrial wall and subsequently draining into the left atrium through a capillary network (patients 1 and 2, fig 1). The second type was in the superior anterior portion of the atrial baffle, incorporating the pectinate muscles of the right atrium and draining into the neoleft atrium. In these patients, the communications fanned out into small channels toward the 
Figure 1 Left panel: right atrial angiogram showing a venous channel (arrow) connecting to the left atrium. Right panel: successful occlusion with spring coils (asterisk).
Figure 2 Left panel: right atrial angiogram defining a short venous channel (asterisk) draining into the neoleft atrium, and fanning out into a small vessel plexus (arrow).

Right panel: attempted occlusion with an umbrella device (arrow).

Figure 3 Left panel: a selective angiogram from the inferior vena cava into a venous channel coursing subdiaphragmatically, connecting to the

pericardial veins (arrows), and then to the left atrium. Right panel: occlusion with spring coils (asterisks).
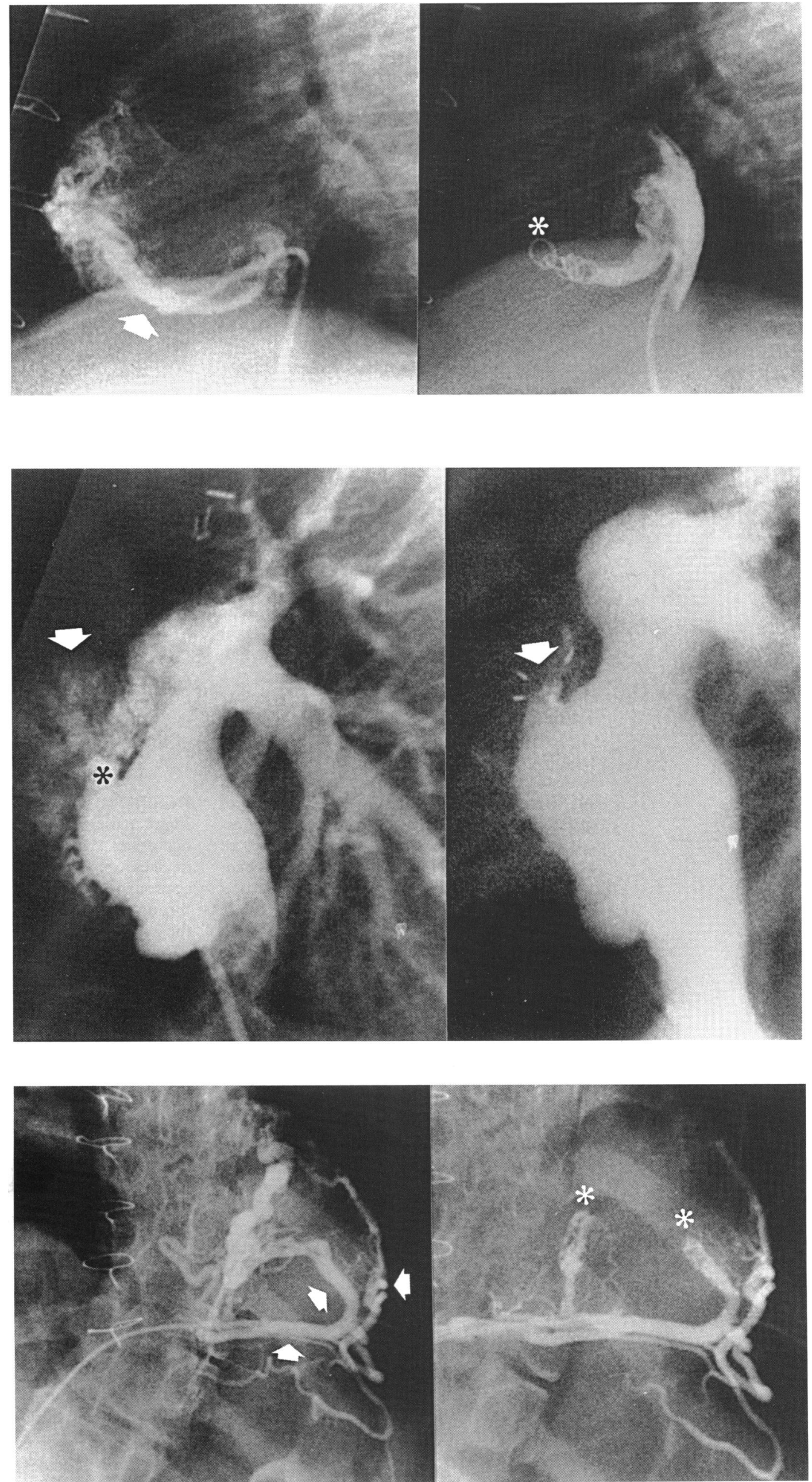
right atrial appendage. In each instance, the shunts were in the superior suture line of a lateral tunnel modification of the Fontan procedure (patients 3 to 7, fig 2) in which the right atrial appendage was incorporated into the left atrium. The third unusual communication was identified in only a single patient; this had vascular channels originating from the inferior vena cava connecting the inferior phrenic veins to the pericardial veins and subsequently to the left atrium, at or close to the ostium of the left pulmonary veins (patient 8 , fig 3 ).

\section{SHORT TERM RESULTS}

Before device occlusion, the aortic oxygen saturation was $88 \%(4) \%$ (range $84 \%$ to $94 \%$ ), and the right atrial pressure was $14(4) \mathrm{mm} \mathrm{Hg}$ (range 10 to $23 \mathrm{~mm} \mathrm{Hg}$ ). All devices were successfully positioned within the venous communications. After occlusion, the aortic oxygen saturation increased to $95 \%(3) \%$ (range $91 \%$ to $100 \%$ ) $(P \ll 0.001)$. There were no significant changes in right atrial pressure after test occlusion or device implantation, and right atrial angiography showed appropriate positioning of all implants. In six patients there was complete shunt obliteration, while in two patients, in whom umbrella devices were used, a small residual right to left leak persisted. No complications were encountered during or immediately after catheterisation.

\section{CLINICAL FOLLOW UP}

The median follow up time was seven months (range one to 17 months). Colour flow Doppler echocardiography $(n=3)$ or catheterisation $(n=2)$ was performed to assess residual shunt flow in these patients. In patient 8, although multiple coil embolisations were performed in the majority of venous channels, there remained several unoccluded feeder vessels to the left atrium, and cyanosis (aortic oxygen saturation $87 \%$ ) recurred. Repeat cardiac catheterisation performed after a four month interval documented a stenotic atrial-pulmonary connection, not apparent from the previous angiographic study. A stent was implanted into this area, after which the mean right atrial pressure fell from 22 to $18 \mathrm{~mm} \mathrm{Hg}$, and aortic oxygen saturation increased to $95 \%$. Of the two patients (patient 3 and 6) with small residual leaks, patient 3 redeveloped cyanosis (aortic oxygen saturation $88 \%$ ) after 12 months, and cardiac catheterisation showed a persistent right to left shunt through or around the previously positioned implant. A second $17 \mathrm{~mm}$ double umbrella device was positioned with complete occlusion. At six months follow up, the aortic oxygen saturation was $93 \%$ at rest, and with exercise testing $92 \%$, and echocardiographically no residual shunting could be identified. In patient 6 , recurrent cyanosis (aortic oxygen saturation $87 \%$ ) was evident by three months follow up, although echocardiographically no interatrial shunt could be identified, probably because of the oblique orientation of the communication. Exercise testing was performed 17 months after initial implantation, and the aortic oxygen saturation was found to be $87 \%$ at rest, falling to $72 \%$ during exercise. Recatheterisation showed numerous right to left communications through the superior portion of the baffle anastomosis. A $17 \mathrm{~mm}$ and a $12 \mathrm{~mm}$ double umbrella device were implanted, with partial but not complete elimination of residual shunting. Nevertheless, resting room air arterial saturation rose from $87 \%$ to $93 \%$. All patients are currently well, with normal growth patterns, and except for patient 6 (recently embolised), no cyanosis with activity has been documented. Formal exercise testing, however, has not been performed in all.

\section{Discussion}

Interatrial venous communications between coronary sinus and left atrium after the Fontan procedure have been reported previously, and the development of right to left shunt from a variety of unusual sources identified and discussed. ${ }^{5-7}$ In this series, we observed unusual large communications originating from the right atrium communicating with the left atrium, not noted before surgery. We believe these communications represent normal vessels that exist under the normal circumstance of low right atrial pressure, and drain toward the right atrium. With the alteration in right atrial haemodynamics, after creation of an atrium dependent circulation, the channels enlarge, with reversal of flow towards the lower pressure left atrium.

Anatomically, the smallest cardiac veins (the so called Thebesian veins) and the anterior cardiac veins are the only cardiac veins that do not communicate with the coronary sinus, draining directly into the right atrium. The Thebesian veins consist of minute vessels that arise from the muscular wall of the heart, course on the anterior surface of the right atrium, and can be found in its internal surface. ${ }^{1314}$ The anterior cardiac veins consist of four small vessels that collect blood from the ventral portion of the right atrium and ventricle, opening separately between the pectinate muscles of the right atrial appendage through one or two orifices. ${ }^{1516}$ Embryologically, the Thebesian veins represent persistence of the sinusoid spaces of the embryonic heart, and the cardiac veins represent an endothelial outgrowth from the left horn of the sinus venosus. Communications between these two venous systems have been documented. ${ }^{17} 18$

In this series, all patients except patient 8 had a total cavopulmonary anastomosis using a lateral tunnel technique, with the orifice of the coronary sinus partitioned to divert flow into the pulmonary venous atrium (left atrium), in an effort to avoid potential impairment of ventricular function by high coronary venous pressure. ${ }^{19}$ To create the lateral tunnel, an incision is made along the superior border of the right atrial appendage, connecting with the pulmonary trunk. The tunnel is then inserted and sutured between vena caval veins within the right atrium, the superior suture 
line border frequently located within the pectinate muscles of the right atrial appendage. ${ }^{20} \mathrm{We}$ speculate that with partitioning of the right atrium, the raised systemic venous pressure creates a stimulus directing flow from that chamber to the lower pressure left atrium through these otherwise normal cardiac veins, resulting in cyanosis. With time these channels enlarge and become tortuous as they accommodate right atrial blood flow, accounting for these angiographic appearance. The third venous channel (patient 8) coursed subdiaphragmatically (similar to the inferior phrenic vein) and connected with the pericardial veins into the posterior wall of the left atrium. We also presume that its presence was stimulated by the raised systemic venous pressure in this patient.

Transcatheter umbrella closure and coil embolisation of congenital or postoperative cardiovasular defects (other than patent ductus arteriosus) ${ }^{621}$ have been well described and proven effective. The patient selection for umbrella or coil occlusion in this setting depended on the size and shape of the venous channel. Three patients with thin long and tortuous communications were ideally suited to spring coil embolisation, and complete occlusion resulted. In the remainder, whose venous channels were shorter and larger, occlusion was achieved with umbrella devices, though residual leaks were found in two of the five. These latter shunts were in part related to the superior suture line of the lateral tunnel and could perhaps be avoided by placement of the suture line outside the margin of the pectinate musculature and appendage. Conceivably, it may be possible to identify and ligate these vessels on the surface of the appendage if seen, although the anatomy is often distorted by scar and fibrosis from previous surgeries.

In all but one patient, the right atrial pressure was not increased beyond levels seen in the majority of patients after creation of an atrium dependent circulation. ${ }^{22}$ Additionally, ventricular morphology, ${ }^{3}$ associated risk factors, ${ }^{23}$ or the effect of atrial fenestration ${ }^{8}$ did not appear to be protective or to predispose to the development of these communications. It would appear that the only commonly experienced event among these patients is an alteration in atrial physiology, though the degree of that alteration is variable. Why one patient might develop these shunts and another not is as yet unclear. Whether, with time, these communications will develop in the long term follow up of patients after the Fontan procedure is speculative, but a matter of concern. $^{22} 24$ These observations support further investigation into the application of the extra-atrial baffle (to conduct inferior caval vein flow over the surface of the right atrium to the pulmonary arteries), although long term problems with this approach have also not been fully defined. ${ }^{25}$

Anomalous atrial venous communications producing right to left shunt, though unusual, are encountered following a total cavopulmonary anastomosis. Although the small number of patients of the present study limits rigorous statistical analysis and the follow up is brief, this review confirms initial clinical experiences suggesting that transcatheter occlusion of such defects represents a technically feasible and effective method of non-surgical intervention.

1 Fontan F, Baudet E. Surgical repair of tricuspid atresia Thorax 1971;26:240-8.

2 Fontan F, Deville C, Quaegebeur J, Ottenkamp J, Sourdille N, Choussat A, et al. Repair of tricuspid atresia in 100 patients. $f$ Thorac Cardiovasc Surg 1983 85:647-60.

3 Coles JG, Kielmanowicz S, Freedom RM, Benson LN, Moes F, Olley PM, et al. Surgical experience with the modified Fontan procedure. Circulation 1987:76(suppl III):III-61-6.

4 Leung MP, Benson LN, Smallhorn JF, Williams WG, Trusler GA, Freedom RM. Abnormal cardiac signs after Fontan type of operation: indicators of residua and sequelae. Br Heart $\mathcal{f}$ 1989:61;52-8.

5 Westerman GR, Readinger RI, Van Devanter SH. Unusual interatrial communication after the Fontan procedure. F Thorac Cardiovasc Surg 1985;90:627-30.

6 Lock JE, Cockerham JT, Keane JF, Finley JP, Wakely PE, Fellows KE. Transcatheter umbrella closure of congenital heart defects. Circulation 1987;75:593-9.

7 Hayes AM, Burrows PE, Benson LN. An unusual cause of cyanosis after the modified Fonton procedure-closure of venous communications between the coronary sinus of venous communications between the coronary sinus
and left atrium by transcatheter techniques. Cardiol Young 1994;4:172-4.

8 Bridges ND, Lock JE, Castaneda AR. Baffle fenestration with subsequent transcatheter closure. Modification of the Fontan operation for patients at increased risk. Circulation 1990;82:1681-9.

9 De Leval MR, Kilner P, Gewillig M, Bull C. Total cavopulmonary connection: a logical alternative to atriopulmonary connection for complex Fontan operations. Experimental studies and early clinical experience. $\mathfrak{f}$ Thorac Cardiovasc Surg 1988;96:682-95.

10 Rashkind WJ, Mullins CE, Hellenbrand WE, Tait MA Nonsurgical closure of patent ductus arteriosus: clinica application of the Rashkind PDA occluder system. Circulation 1987;75:583-92.

11 Nykanen DG, Hayes AM, Benson LN, Freedom RM Transcatheter patent ductus arteriosus occlusion: application in the small child. $f \mathrm{Am}$ Coll Cardio 1994;23:1666-70.

12 Lock JE, Keane JF, Fellows KE. Diagnostic and interventional catheterization in congenital heart disease. Boston: Martinus Nijhoff 1987:126-33.

13 Esperanca-Pina JA, Dos Santos Ferreira A. Micro-angiographic aspects of the thebesian veins. Acta Anat 1974;88:156-60.

14 Esperanca-Pina JA, Correia M, O’Neill JG. Morphological study on the thebesian veins of the right cavities of the heart in the dog. Acta Anat 1975;92:310-20.

15 Esperanca-Pina JA. Morphological study on the human anterior cardiac veins, venae cordis anteriores. Acta Anat 1975;92:145-59.

16 Bezuidenhout AJ. The coronary circulation of the heart of the ostrich (Struthio camelus). F Anat 1984;138:385-97.

17 Wearn JT. The role of the thebesian vessels in the circulation of the heart. F Exp Med 1928;47:293-316.

18 Grant RT. Development of the cardiac coronary vessels in the rabbit. Heart 1926;13:261-72.

19 Ilbawi MN, Idriss FS, Muster AJ, DeLeon SY, Berry TE, Duffy CE, et al. Effects of elevated coronary sinus pressure on left ventricular function after the Fontan operation. An experimental and clinical correlation. $f$ Thora Cardiovasc Surg 1986;92:231-7.

20 Sade RM. Surgical options in univentricular atrioventricular connection. In: Jacobs ML, Norwood WI, eds. Pediatric cardiac surgery. Boston: ButterworthPediatric cardiac surgery.

21 Perry SB, Radtke W, Fellows KE, Keane JF, Lock JE. Coil embolization to occlude aortopulmonary collateral vessels and shunts in patients with congenital heart disease. f Am Coll Cardiol 1989;13:100-8.

22 Driscoll DJ, Offord KP, Feldt RH, Schaff HV, Puga FJ, Danielson GK. Five- to fifteen-year follow-up after Fontan operation. Circulation 1992;85:469-96.

23 Kirklin JK, Blackstone EH, Kirklin JW, Pacifico AD Bargeron LM. The Fontan operation. Ventricular hypertrophy, age and date of operation as risk factors. $f$ Thorac Cardiovasc Surg 1986;92:1049-64.

24 Fontan F, Kirklin JW, Fernandez G, Costa F, Naftel DC, Tritto F, et al. Outcome after a "perfect" Fontan operation. Circulation 1990;81:1520-36.

25 Giannico S, Corno A, Marino B, Cicini MP, Gagliardi MG, Amodeo A, et al. Total extracardiac right heart bypass. Circulation 1992;86(suppl II):II-110-7. 